\title{
Effectiveness of $A \beta$ classification of diabetes prone to ketosis in real clinical practice
}

\author{
Volkova N.I., Porksheyan M.I.,Rudakova J.A., Kanaeva S.A.. \\ Rostov State Medical University, Rostov on Don, Russia
}

\section{OBJECTIVES}

Prevalence of so-called diabetes prone to ketosis (DPK), has been increasing. The necessity of lifelong insulinotherapy is determined by $A \beta$ classification of DPK.

\section{METHODS}

- 7 patients with atypical course of T2DM were studied.

- All patients had gradual development of hyperglycemia, obesity 1-2 stage, and acetonuria

- Noone had acute weight loss.

- 3 had positive GAD-AB, 4 - negative.

- Initially all patients were treated by insulin during 2-3 weeks. Thereafter, C-peptide was determined and type of diabetes, prone to ketosis, was established. If C-peptide was more than $1.2 \mathrm{ng} / \mathrm{ml}$, oral hypoglycemic drugs were prescribed.

- Patients were followed up during 1 year with studying BMI, C-peptide, HbA1c, acetonuria

\section{RESULTS}

\section{3 patients with} diagnosis of $A+\beta+D P K$ with oral hypoglycemic drugs initially and then switched to insulin (after

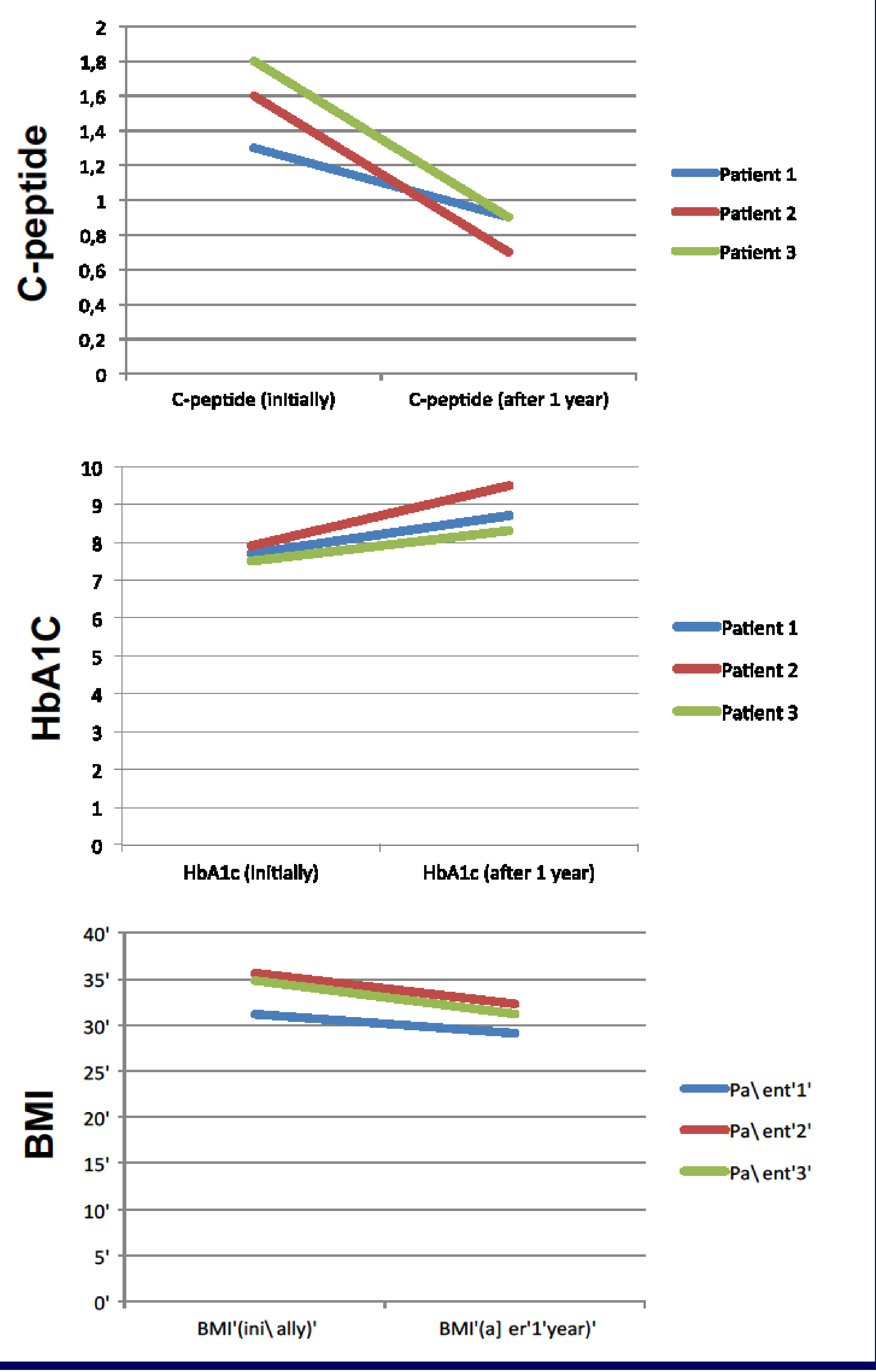

References

1. Balasubramanyam A., Nalini R. Hampe CS, Maidoado M. Syndromes od ketosis-prone diabetes melitus. Endocr rev 2008; 29:292

\section{4 patients with diagnosis of $A-\beta+D P K$}

with oral hypoglycemic drugs during 6 months
2 patients

continued oral hypoglycemic drugs
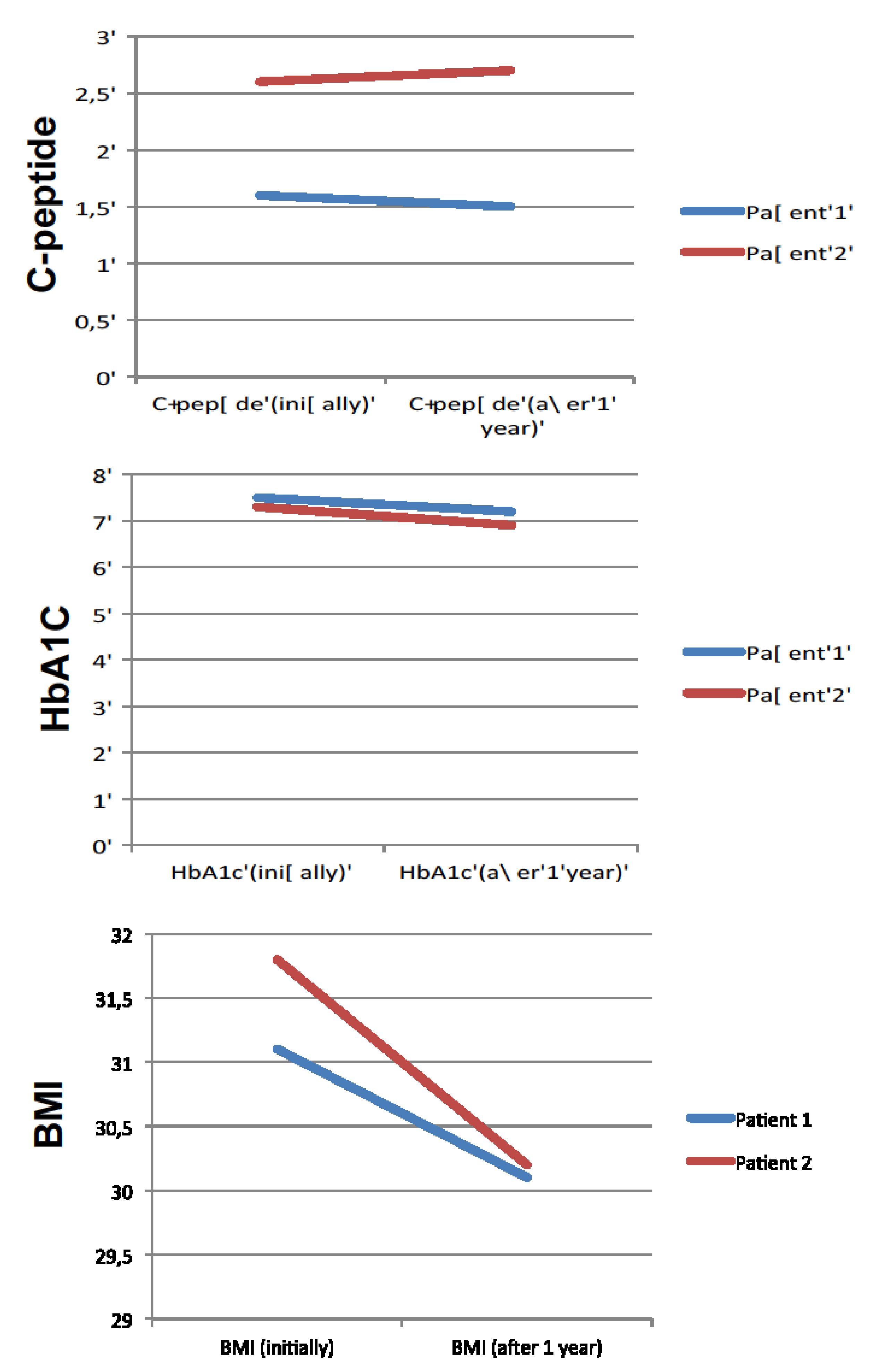

2 patients switched to insulin

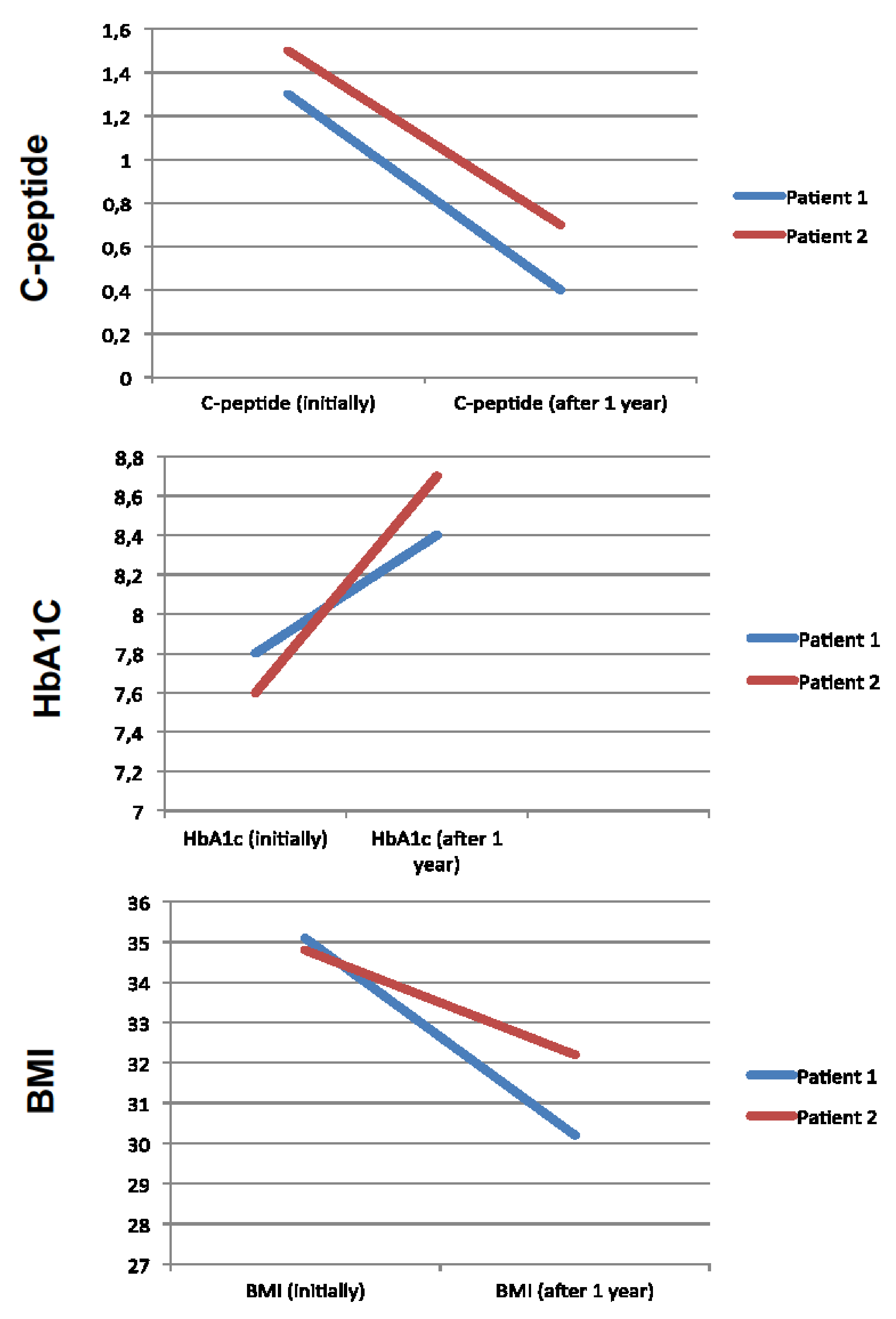

\section{CONCLUSIONS}

Current $A \beta$ classification of DPK is thought to allow to determine necessity of yearlong insulinotherapy, which were not proved in our pilot study. The more clinical experience is needed to make strict follow up and treatment recommendations for patients with atypical diabetes. 